University of New Hampshire

University of New Hampshire Scholars' Repository

4-10-2016

\title{
An information technology competency model and curriculum
}

John Impagliazzo

Hofstra University

Mihaela C. Sabin

University of New Hampshire, Durham, mihaela.sabin@unh.edu

Hala Alrumaih

Al Imam Mohammad Ibn Saud Islamic University

Follow this and additional works at: https://scholars.unh.edu/unhmcis_facpub

\section{Comments}

This is an Author's Original Manuscript of an article published by IEEE in Global Engineering Education Conference

(EDUCON), 2016 IEEE in 2016, available online: https://dx.doi.org/10.1109/EDUCON.2016.7474657

\section{Recommended Citation}

John Impagliazzo, Mihaela Sabin, Hala Alrumaih, and Barbara Viola, An information technology competency model and curriculum, Global Engineering Education Conference (EDUCON), 2016 IEEE, EDUCON2016, IEEE, 2016, pp. 892-895.

This Article is brought to you for free and open access by the Applied Engineering and Sciences at University of New Hampshire Scholars' Repository. It has been accepted for inclusion in Applied Engineering and Sciences Scholarship by an authorized administrator of University of New Hampshire Scholars' Repository. For more information, please contact Scholarly.Communication@unh.edu. 


\section{An Information Technology Competency Model and Curriculum}

\author{
John Impagliazzo \\ Department of Computer Science \\ Hofstra University \\ Hempstead, New York, USA \\ John.Impagliazzo@Hofstra.edu \\ Mihaela Sabin \\ University of New Hampshire \\ 88 Commercial Street \\ Manchester, New Hampshire USA \\ mihaela.sabin@unh.edu
}

\author{
Hala Alrumaih \\ College of Computer and Information Sciences \\ Al Imam Mohammad Ibn Saud Islamic University \\ Riyadh, Saudi Arabia \\ hala.alrumaih@ccis.imamu.edu.sa
}

\author{
Barbara Viola \\ Viotech Solutions Inc. \\ 1111 Route 110 \\ Farmingdale, New York USA \\ bviola@viotechsolutions.com
}

\section{CONTEXT OF INFORMATION TECHNOLOGY}

-This paper addresses the progress made by the Association for Computing Machinery (ACM) and the IEEE Computer Society (IEEE-CS) in developing a competency model and curricular guidelines for four-year degree programs in information technology. The authors are members of an international task group representative of academic institutions, industry, and professional organizations. The task group is to develop a competency model, called IT2017, for information technology education within two years based on earlier guidelines and other perspectives. This paper provides a brief background of the project, some activities undertaken, the progress made, and expectations for future developments. IT2017 seeks to produce a futuristic model of academic excellence so information technology graduates will be prepared for new technological challenges in a global economy.

Keywords-information technology; competency model; IT curricula; IT competencies; IT industries

\section{INTRODUCTION}

In 2008, Association for Computing Machinery (ACM) and the IEEE Computer Society (IEEE-CS) published the first model curriculum report for undergraduate degree programs in information technology (IT), called IT2008 [1]. Since that time, many new technologies emerged and flourished. In 20122013, ACM formed an exploratory committee to determine whether IT2008 required updating. After an affirmative response, ACM/IEEE-CS formed a task group charged with developing an update to IT2008 that was appropriately forward looking for IT graduates in the mid-2020s. The report, tagged IT2017, would encompass technology and educational advances that occurred since 2008 [2]. The IT2017 task group plans to produce a competency model and curricular guidelines for worldwide four-year IT degree programs that prepare graduates professionally for current and new technologies for the next decade.
The information age provides wide access to computing and communication technologies that enable new scientific discoveries and the creation of many new technologies. This has led to multiple understandings of IT.

\section{A. Some Definitions of IT}

A definition of IT should include global perspectives with multicultural and multidisciplinary teamwork, people (soft) skills, best practices, guidelines, and regulations. The IT2008 model curriculum definition states:

Information Technology (IT) in its broadest sense encompasses all aspects of computing technology. IT, as an academic discipline, is concerned with issues related to advocating for users and meeting their needs within an organizational and societal context through the selection, creation, application, integration and administration of computing technologies [3].

Another more expansive definition is:

Information technology (IT) is the application of computers and telecommunications equipment to store, retrieve, transmit and manipulate data, often in the context of a business or other enterprise [4].

Academia views information technology as a pathway leading to an endpoint such as:

...undergraduate degree programs to meet the computer technology needs of business, government healthcare, schools, and other kinds of organizations [5]

With the expectation that by 2022 computing occupations will increase by $17.7 \%$ and information security will dominate job requirements by $36.5 \%$ [6], we foresee that, regardless of its definition, information technology will be a permanent fixture in academic study and industry quests 


\section{B. Global Perspectives}

In some countries such as Saudi Arabia the meaning of IT is similar to the United States [7]. Aligned with the Digital Agenda for Europe, Germany uses information and communication technology (ICT) to reflect an expanded scope of IT that includes broadcasting and communications technologies [8]. China considers IT as "a wide range of industries such as hardware, software, electronics, semiconductors, internet, telecom equipment, e-commerce, and unlimited computing services" [9]. In Japan, IT focuses on developing a business strategy that utilizes IT to ensure the stable operation of the information systems that create safe and reliable service-driven industries [10]. To understand the global similarity of IT, a review of leading job websites shows that global companies (e.g., IBM, Microsoft, Cisco, and Intel) hire IT professionals with the same requirements, regardless of country.

\section{FACULTY AND INDUSTRY SURVEYS}

The IT2017 task group decided to conduct a faculty survey and an industry survey to ascertain multinational indicators, predictors, and sources surrounding information technology as an academic discipline and industry sector. Through ACM, the task group contacted almost sixteen thousand computing faculty members from computing departments worldwide. It also surveyed close to two thousand industry professionals from the United States. The surveys captured opinions of faculty members and industry professionals to implement programs that prepare highly competitive IT graduates for the 2020s.

The task group designed the surveys and, with ACM support, identified participating faculty from U.S. and non-U.S. academic computing programs. The Association for Information Technology Professionals (AITP) identified industry professionals. Survey data took into account a range of factors: location and size of the survey participants' institutions, sources of external student transfers, areas of mathematics and science subjects, credit-bearing internship experience, percent of technical IT component of the full undergraduate degree program, and IT competency areas of importance.

The survey yielded almost six hundred faculty responses and over ninety industry responses. These responses showed some commonalities as well as some remarkable differences. For example, while faculty members indicated programming was the most important competency, industry practitioners believe that cybersecurity and digital forensics were most important. Industry participants highly valued soft skills and project management. The surveys also showed that more IT programs with stronger math, science, and IT coursework requirements reside outside the United States.

\section{TASK GROUP ACTIVITIES}

\section{A. Previous Curricular Reports}

The IT2017 task group has incorporated the results of previous curricular reports as a backdrop for its activities. These include reports on computer science, information systems, and software engineering. Paramount in this inclusion is the IT2008 report [1] and the CC2005 computing curriculum overview report [11]. Both of these reports have achieved international acclaim.

\section{B. Survey Reflections}

It was interesting to note that of the responses from the faculty survey naming a degree discipline in English, 61\% were from outside the United States. This reflects the fact that a majority of the responses had a keen interest in the IT2017 project and the nature of information technology in general. Of interest is the variety of program names with 234 distinct names from a total response of 833 names.

With respect to the top skills expected of new IT graduates, industry responses indicated that the top three areas are (1) soft skills, (2) project management, and (3) information security. Faculty responses for the most important content areas of the IT curriculum indicated (1) programming, (2) web systems and technologies, (3) networking, (4) big data, and (5) cloud computing.

Credit bearing internships are available throughout the academic programs of the surveyed faculty. However, for those programs outside the United States, industry experience is more of a requirement than an elective. The presence of a required industry experience is generally prevalent in most IT programs at non-US universities.

With regard to mathematical requirements, the top three rankings are (1) discrete mathematics, (2) statistics, and (3) applied calculus. Little difference exists between U.S. and nonU.S. responses. However, opinions vary regarding the amount of mathematics needed. It was clear that non-U.S. IT programs require more mathematics than U.S. programs do. One could conclude that IT programs in non-U.S. settings are more rigorous than U.S. programs and perhaps the level of presentation of IT experiences and courses are more theoretical than applied.

With respect to subject intensity, the data show that the vast majority of responses required that at least $30 \%$ of a student's degree coursework relate to IT. It is not surprising, however, that non-U.S. institutions have stricter requirements regarding IT courses where two-thirds of responses required more than $50 \%$ concentration in IT.

\section{Competencies and Knowledge}

Based on survey data and other materials, the IT2017 task group decided to ignore topics and focus instead on competencies and learning outcomes. As a result, it has replaced knowledge units with competency units and knowledge areas with competency areas.

The reason for these changes is that knowledge alone is not sufficient to produce a competent graduate for the mid-2020s. Competency implies knowledge coupled with ability and skills, which is exactly what budding IT professionals need in an ever-changing technology landscape. Hence, the new IT curricular guidelines propose and promote an IT competency model.

\section{CURREnt IT COMPETEnCY MODEL}

The evolving IT competency model has a three-level hierarchical structure. The highest level of the hierarchy is the competency area (CA), which represents a particular disciplinary IT subfield, $\underline{n o t}$ a course. These areas are broken down into smaller divisions called competency units, which represent individual strands within an area. In turn, each 
competency unit identifies a set of competencies that represents the lowest level of the hierarchy.

\section{A. Essential and Applied Competency Areas}

One of the task group's goals in updating the IT2008 report is to keep the required component of the competency model as small as possible. To implement this principle, the task group distinguishes between essential and applied competency areas. Essential competencies are competencies that anyone obtaining a four-year IT degree must acquire. Applied competency areas give IT programs choices, flexibility, and identity. Students are expected to acquire some subset of the applied competencies according to the goals of a program.

TABle 1. EsSEntial AREAS of the IT COMPETENCy Model

\begin{tabular}{|c|c|}
\hline Essential Competency Areas & Hours \\
\hline Cybersecurity Principles & 40 \\
\hline Global Professional Practice & 25 \\
\hline Information Management & 40 \\
\hline Integrated Systems Technology & 20 \\
\hline Networking & 35 \\
\hline Platform Technologies & 15 \\
\hline Software Fundamentals & 30 \\
\hline System Administration and Maintenance & 20 \\
\hline System Integration and Architecture & 20 \\
\hline User Experience Design & 20 \\
\hline Web and Mobile Systems & 25 \\
\hline & 290 \\
\hline
\end{tabular}

The essential areas of the IT competency model appear in Table 1. The applied areas of the IT competency model appear in Table 2. As with the essential areas, the selection of these applied areas reflects long discussions based on the task group activities, prior publications, surveys, and other resources. Programs should utilize any combination of these application areas to tailor their offerings so they reflect a program's mission, goals and objectives, and the constituents it serves.

TABLE 2. APPLIED AREAS OF THE IT COMPETENCY MODEL

\begin{tabular}{|c|c|}
\hline Applied Competency Areas & Hours \\
\hline Applied Networks & 30 \\
\hline Cloud Computing & 30 \\
\hline Cybersecurity Evolving Challenges & 30 \\
\hline Data Scalability and Analytics & 30 \\
\hline Internet of Things & 30 \\
\hline Mobile Applications & 25 \\
\hline Social Responsibility & 20 \\
\hline Software Development and Management & 20 \\
\hline Virtual Systems and Services & 30 \\
\hline
\end{tabular}

\section{B. Temporal Considerations}

To give readers a sense of the time required to cover a particular area, the IT2017 task group has chosen to express time in hours (contact hours). One hour corresponds to the inclass time required to present the material on a topic in a traditional lecture-oriented format. Hence, one "hour" or one lecture hour, is one 50-minute period. The hours listed in Table 1 and in Table 2 represent a minimal level of exposure needed to achieve each competency area.
It is important to note that the IT2017 task group does not seek to endorse the lecture format, even though it has used a metric with roots in a classical, lecture-oriented form. Given recent improvements in educational technology, other modes can be effective. The time specifications serve as a comparative metric, in the sense that 5 hours presumably takes approximately five times longer to achieve competency in a given unit than 1 hour. For example, in Table 1, learning activities in the competency area of Software Fundamentals (30 hours) should be double to the learning activities in the Platform Technologies (15 hours) competency area.

The hours do not include either the time instructors spend on their own to prepare for their teaching and evaluate student performance or the time students spend on their own to an achieve the learning outcomes for an essential or applied competency area. For a traditional classroom setting, a general guideline is that the amount of out-of-class time is approximately three times the amount of in-class time. For example, in Table 2, the applied competency area of social responsibility ( 20 hours) implies sixty more hours of additional study for a total of eighty hours for this learning experience.

\section{Scope and Competency Units}

Each competency area, essential or applied, includes several statements that describe the area scope. These are high-level declarations outlining the general description of the competency area. Table 3 shows the set of area scope statements for the information management essential competency area (Table 1). Thus, it is easy to determine the significance of this competency area by simply reading the five scope statements.

TABLE 3. AREA SCOPE FOR INFORMATION MANAGEMENT CA

\begin{tabular}{|c|l|}
\hline$\#$ & \multicolumn{1}{|c|}{ Scope Statements } \\
\hline 1 & $\begin{array}{l}\text { Tools and techniques for efficient data modeling, } \\
\text { collection, organization, retrieval and management } \\
2\end{array}$ \\
3 & $\begin{array}{l}\text { Extracting information from data to make data } \\
\text { meaningful to the organization } \\
\text { Developing, deploying, managing and integrating data } \\
\text { and information systems to support the organization } \\
4\end{array}$ \\
5 & $\begin{array}{l}\text { Safety and security issues associated with data and } \\
\text { information } \\
\text { Tools and techniques for producing useful knowledge } \\
\text { from information }\end{array}$ \\
\hline
\end{tabular}

In addition to the area scope, each competency area contains a set of competency units that identify the specific breakout of the competency area. Table 4 shows the set of competency units for the information management competency area. In this case, seven competency units define this area.

\section{Competencies}

Each competency unit consists of a set of competencies that indicate what students should know or do relative to the competency unit. As an example, Table 5 shows the six competencies related to the database query languages competency unit for the information management competency area. Note that each competency is written as an imperative sentence and it begins with action verb suggesting the performance expectation from a student. 
TABLE 4. COMPETENCY UNITS FOR THE INFORMATION MANAGEMENT COMPETENCY AREA

\begin{tabular}{|c|c|}
\hline Information Management & Hours \\
\hline History and overview & 1 \\
\hline Data-information concepts & 6 \\
\hline Data modeling & 9 \\
\hline Database query languages & 9 \\
\hline Data organization architecture & 8 \\
\hline Special-purpose databases & 2 \\
\hline Managing the database environment & 5 \\
\hline Total: & 40 \\
\hline
\end{tabular}

TABLE 5. COMPETENCIES FOR DATABASE QUERY LANGUAGES CU

\begin{tabular}{|c|c|}
\hline \# & Competencies \\
\hline a & $\begin{array}{l}\text { Create, modify and query database objects using the } \\
\text { Structured Query Language (SQL). }\end{array}$ \\
\hline b & $\begin{array}{l}\text { Filter and sort data using various clauses including } \\
\text { where, order by, between, like, group by and having. }\end{array}$ \\
\hline$c$ & Use joins to select data across multiple tables. \\
\hline c & Use embedded SQL queries. \\
\hline$e$ & $\begin{array}{l}\text { Perform calculations in a query using calculated fields } \\
\text { and aggregate functions. }\end{array}$ \\
\hline & Create updatable and non-updatable views. \\
\hline
\end{tabular}

\section{BUILDING A CURRICULUM}

A draft of the complete competency model (version 0.50) appears at the IT2017 project website [12]. The competency model (areas, units, scope and competencies) forms the foundation of any curriculum in information technology. The task group recommends a total of 420 hours, which includes the eleven essential competency areas that contain 290 hours (Table 1) plus any combination of applied areas that complements essential competency areas with at least 130 additional hours from 245 total applied competency hours (Table 2). The 420 (contact) hours represent approximately one year or thirty semester hours of study period. The task group also recommends that an IT program should contain at least 90 hours of mathematics that includes discrete mathematics plus some relevant science experience. The 90 (contact) hours of mathematics represent the equivalent of six semester hours or two courses. Where applicable, other student experiences would constitute a complete program leading to an IT degree.

The aforementioned discussion is sufficient to generate a modern curriculum for information technology. Programs are able to weave the competencies from essential and applied areas within a set of student learning experiences. Since the competency areas are not courses, programs could address the related competency units over two or more courses. The IT2017 report will provide examples on how to undertake this activity.

\section{CONCLUSION}

Considering how IT developed and evolved over the past several decades, it is apparent that IT has transitioned from being a new part of the infrastructure in advanced countries to an essential part of the infrastructure. Progress in all areas of human endeavor continues to benefit from the application of
IT, and it does not appear that this trend will end nor even decrease. Moving computing to the masses has opened up doors into finding ways to solve many perplexing problems. The IT2017 task force members believe IT will continue to be an essential part of a global economy and will drive discovery, innovation, and human expression worldwide. Competent graduates from IT programs will be in great demand.

The question remains: are current programs producing the best graduates possible to meet the world challenges of the mid 2020s? The task group does not believe so and it is striving to produce curricular recommendations that generates the ultimate graduate who can meet and adapt to a changing computing field and who has the opportunity to do advanced studies for the betterment of humanity. The focus on a competency-based curriculum is a giant step toward fulfilling that goal

\section{ACKNOWLEDGEMENTS}

The members of the IT2017 task group thank the professional societies and in particular the ACM for its generous support in organizing and executing the international survey. Their thanks go also to Paul Snow, who has tirelessly supported this study with statistical analysis work.

\section{REFERENCES}

[1] Lunt, B. M., Ekstrom, J. J., Gorka, S., Hislop, G., Kamali, R., Lawson, E., LeBlanc, R., Miller, J., Reichgelt, H. 2008. Curriculum Guidelines for Undergraduate Degree Programs in Information Technology. Technical Report. ACM, New York, NY, USA.

[2] Sabin, M., Alrumaih, H., Impagliazzo, J., Lunt, B., Zhang, M. 2015. Designing an Information Technology Curriculum Framework to Prepare Successful Graduates in 2025. In Proceedings of the 2015 conference on Innovation \& technology in computer science education (ITiCSE'15). ACM, New York, NY, USA

[3] Lunt B., et al., Information Technology 2008: Curriculum Guidelines for Undergraduate Degree Programs in Information Technology; https://www.acm.org//education/ curricula/IT2008\%20Curriculum.pdf. Accessed 2015 Jul 04.

[4] Daintith J., ed (2009), A Dictionary of Physics, Oxford University Press.

[5] Massy W. and Zemsky R. 1995. Using information to Enhance Academic Productivity Educause; http://net.educause.edu/ir/library/html/ nli0004.html. Accessed 2015 Jul 04.

[6] Bureau of Labor Statistics;_http://www.bls/gov/emp/ep_table_102.htm. Accessed 2015 Jul 04

[7] Communications and Information Technology Commission (CITC) 2014. Annual IT Report in the Kingdom of Saudi Arabia; http://www.citc.gov.sa/english/Reportsandstudies/Reports/Pages/ITReport.aspx. Accessed 2015 Jul 05.

[8] Digital Agenda for Europe - A Europe 2010 Initiative. Germany, a world leader in technology, engineering and innovation. 2012; http://ec.europa.eu/digital-agenda/en/news/germany-world-leadertechnology-engineering-and-innovation. Accessed $2015 \mathrm{Jul} 04$.

[9] Zhang M. and Zhang L. Undergraduate IT education in China. 2014. ACM Inroads, 5, 3\: 49-55.

[10] Basic knowledge of basic information technology's test; http://skillstyle.com/license/johoshori-it/IT-zenpan/kihon-jyoho-gijutsusha.html. Accessed 2015 Jul 05.

[11] ACM/IEEE Overview report, CC2005. http://www.acm.org/education/ education/curric_vols/CC2005-March06Final.pdf. Accessed 2015 Jul 05 .

[12] IT2017, Public website; http://it2017.hosting.acm.org/. Accessed 2015 Nov 10. 